\title{
La protección contra los corsarios: el recinto fortificado de Mascarell
}

\author{
Maria Emilia Casar Furio ${ }^{a}$, Maria Teresa Broseta Palanca ${ }^{b}$
}

Departamento de Urbanismo de la Universitat Politècnica de València, Valencia, España, 'amacafu@urb.upv.es, bmabropa@urb.upv.es

\begin{abstract}
Along the sixteenth century, Valencian coasts used to suffer continuous attacks by Berber pirates, which brought an extensive network of watchtowers to warn against the invaders. In the case of Mascarell, a small town located $4 \mathrm{~km}$ away from the coast, a walled enclosure with two doors and four towers is the option to ensure the safety of its inhabitants.

Many restoration works have been developed along the time; although they were not always according to preservation criteria at the earlier periods, other good later preservation policies have been established like the special protection plan for the old quarter, the reconstruction of the fallen pieces, and the intervention in rebuilt areas with brick in the seventies, trying to recover the old enclosure appearance, with a variety of native technique of wall called Valencian Tapia. About the wall first construction, the contract of works of 1553 is preserved, which is not only an excellent source of knowledge about the its history and its constructive features, but also it shows the danger of periodic invasions since the contract establishes the need to guard the site before starting the wall works every day.
\end{abstract}

Keywords: Historic District, wall, fortification, rammed earth, Mascarell, Comunidad Valenciana.

\section{Introducción}

En líneas generales, la existencia del poblado de Mascarell podría datarse al menos desde 1310, aunque su fundación podría remontarse al año 1238, cuando el rey Jaime I el Conquistador finaliza su campaña, y son los sarracenos expulsados de Burriana los primeros habitantes de la población, conforme al Llibre dels Fets. En el capatró de peites del término de la villa de nules, del año 1529, según los estudios de Felipe Sempere, aparecen 128 propietarios residentes en Mascarell, hasta que en 1609 , cuando se produce la expulsión de los moriscos, el caserío quedó prácticamente abandonado. Durante la época foral, como las demás poblaciones de la baronía, Mascarell se regía según las ordinacions y establiments de la vila de Nules, aunque dispuso de Ayuntamiento propio hasta el 16 julio 1872, cuando se acordó su anexión a Nules.

Durante la segunda mitad del XIX, se produce la recuperación demográfica, con más de 400 habitantes, si bien, a finales de siglo y tras sufrir una devastadora epidemia de cólera, la población queda reducida a la mitad. Será a finales del XIX, cuando D. Pascual Madoz redactó su monumental Geografía, con una población de 90 vecinos y 450 almas, y, el caserío estaba formado por un centenar de casas produciéndose numerosos hallazgos de antigüedades romanas.

El punto álgido de la población será en 1970, con 472 habitantes pero, a partir de ese momento, se inicia un periodo de lenta pero 
constante disminución del número de habitantes que se mantiene hasta la actualidad.

En consecuencia, será Elías Tormo en $1927^{1}$, quien en su guía Levante, hable de las murallas de Mascarell como ejemplo de recinto fortificado (en relación a la arquitectura gótica).

\subsection{El contrato de las obras de la muralla de Mascarell de 1553 constituido como documento de singular importancia para el conocimiento histórico-constructivo}

En el referido contrato $^{2}$ se recoge el método constructivo, que no es otro que la tapia valenciana, esto es, tapia de tierra y costra con medio ladrillo de espesor en las caras interior y exterior de la paredes, material que se describe con claridad, y se llevó puntualmente a la práctica, aunque por diversos acontecimientos se ejecutaron posteriores reparaciones, no todas documentadas, que han perjudicado la unidad primigenia de la cinta muraria.

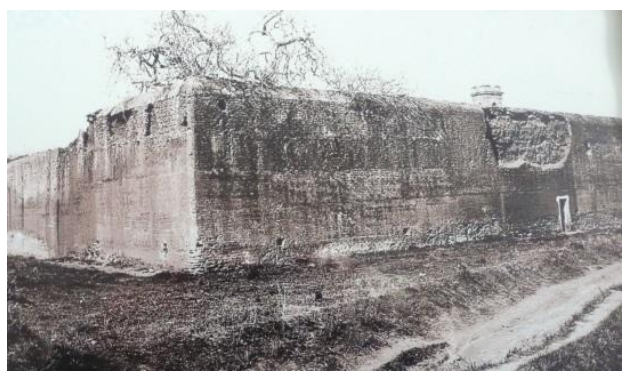

Fig. 1- Vista de los frentes norte y oeste de la muralla. Catálogo de monumentos y conjuntos de la Comunidad Valenciana. Consellería de Cultura, Educación y Ciencia de la Generalidad Valenciana, Servicio de Patrimonio Arquitectónico, 1983.

Más concretamente, en la actualidad las características esenciales de la muralla se describen en el contrato, tratándose de cuatro lienzos en medio de los cuales se construyen elementos salientes de mayor altura, que se califican de torres, o "revellins". El recinto se cerraba mediante dos puertas, protegidas por sendas torres, que conducen, tangencialmente, a los dos muros laterales del Ayuntamiento mediante calles no alineadas según un eje central como las ciudades ideales descritas por
Eiximeniç, que apostaban por una mayor regularidad y una decidida simetría. Las torres apenas sobresalían sobre la altura de la muralla, y disponían en su parte inferior de tres troneras abocinadas, realizadas con sillería.

En la arquitectura defensiva de nuestra Comunidad, la tapia será sin duda la técnica constructiva más empleada, siendo Mascarell el ejemplo en el que se puede contemplar una extensa aplicación, y un relativo buen estado de conservación, de esta evolución de la tapia acerada, denominada tapia valenciana.
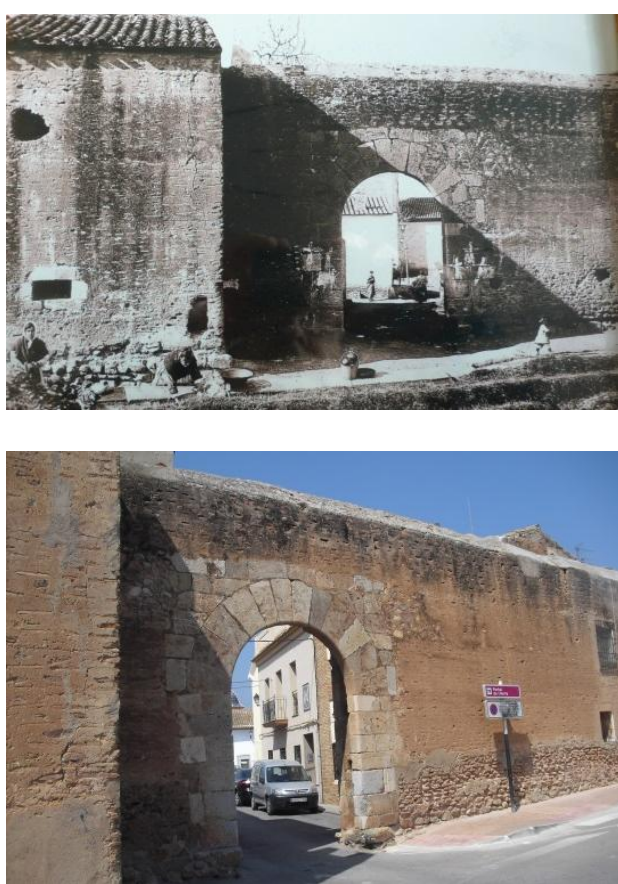

Fig. 2- Vistas de la puerta de l'Horta. La primera enmarcada en el bar del pueblo, de autor y fecha desconocidos. La segunda de su estado actual.

\subsection{El Conjunto Histórico y su especial protección $^{3}$}

Mascarell, constituye un Conjunto Histórico castellonense declarado Bien de Interés Cultural ${ }^{4}$ en el año 1949, por lo que dentro de la normativa de protección de estos bienes en la ley de patrimonio cultural valenciano en estrecha coordinación con la normativa urbanística refiere a la figura del Plan Especial $^{5}$ de 
Protección que ha potenciado las medidas de rehabilitación integrada de esta importante muestra de nuestro patrimonio cultural.

En diciembre de 1992 se acordó la adjudicación del plan especial de protección con arreglo a las estipulaciones redactadas al efecto. El contenido básico del plan especial, de acuerdo con el pliego de condiciones técnicas elaborado por la Consellería de Cultura, Educación y Ciencia de la Generalitat valenciana, debía contemplar una serie de medidas entre ellas la catalogación según lo dispuesto en el artículo 21 LPHE, de los elementos unitarios, inmuebles o espacios libres y estructuras urbanas significantes, dejando en cada caso el tipo de protección estableciendo el nivel adecuado de intervención.

A mayor abundamiento, con la redacción del Plan Especial se acomete un esfuerzo muy importante de toma de datos y de elaboración de propuestas para la puesta en valor del conjunto. Como medidas de protección frente a intervenciones no respetuosas, se elabora el catálogo conforme al artículo $21 \mathrm{LPHE}^{6}$, con la inclusión de los tres inmuebles más significativos: la muralla, la iglesia parroquial y el antiguo Ayuntamiento. A cada inmueble se le asigna un nivel posible de intervención, definido en el cuerpo de la ordenanza, protección integral para la muralla y protección global para la iglesia y el Ayuntamiento.

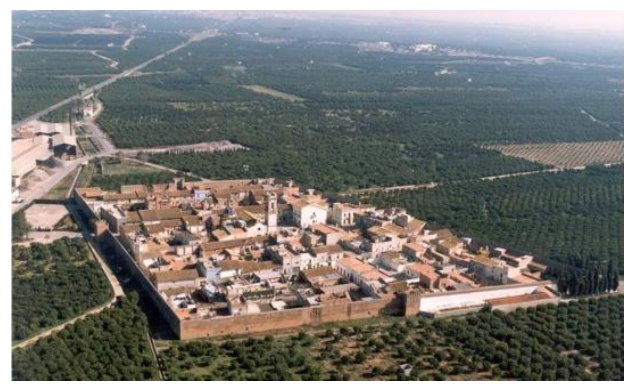

Fig. 3.- Recinto amurallado de Mascarell. 1990.

En suma, las operaciones de transformación en el conjunto histórico deben mantener sus características esenciales (parcelación, altura total, altura de entreplanta, volumen, colores, distribución de huecos, decoración, tratamiento de fachada y cubierta), dado que su interés ambiental está fuertemente deteriorado tanto por la cantidad de elementos impropios contenidos en los paramentos que la conforman, como por la pobreza de su acondicionamiento urbano.

En el caso que nos ocupa, lo cierto es que la catalogación y medidas concretas del plan especial, como el mantenimiento de alineaciones y parcelación como base de la estructura urbana, la delimitación de un entorno de protección y la inclusión de espacios públicos y de equipamiento, han conseguido en parte la conservación del conjunto amurallado, no obstante, la no aprobación de la ordenanza tabulada como documento integrante del plan especial, ha permitido intervenciones no respetuosas con el entorno, y la apropiación del muro por parte del vecindario, lo que ha ido desvirtuando la imagen primigenia de la cerca, que en estos momentos se encuentra necesitada de una cuidadosa y eficaz intervención.

\section{Las intervenciones de restauración en la muralla}

Varias han sido ido las obras de restauración en el muro en distintos momentos de la historia, con aplicación de diferentes criterios, no siempre con técnicas respetuosas con el patrimonio, que junto a las invasiones que ha sufrido la tapia por las viviendas colindantes, no han beneficiado a su conservación.

\subsection{La herencia del patrimonio intervenido}

La primera intervención documentada de restauración y rehabilitación en el conjunto y su muralla, data de 1942 por el Organismo Estatal Regiones Devastadas dependiente del Ministerio de la Vivienda. El proyecto de reparación nos proporciona una inestimable información sobre el conjunto finalizada la guerra civil, con importantes vacíos en su zona sur, a partir del primer levantamiento preciso a escala 1/500 del parcelario, proveniente del archivo general de la Generalitat (Taberner, Broseta, 2011).

Se ejecuta en el interior del recinto una importante intervención: se edifica un nuevo edificio escolar y se restaura el interior de la iglesia, también se restaurarán los desperfectos de sus murallas y los sillares que enmarcaban la 
puerta de Valencia fueron sustituidos en buen número. (Pocos años más tarde se mutila las dos dovelas para ampliar su hueco y permitir el acceso de camiones al interior del recinto).

En los años setenta se realizaron importantes obras de reconstrucción fundamentalmente en los lienzos sur, este y parte del norte, utilizándose la fábrica de ladrillo perforado sin que se tengan noticias del tipo de relleno que se utilizó en su interior. Se reconstruyeron las torres, dotándolas de unas desproporcionadas almenas, y de una altura muy superior a la que debieron de tener en su origen de acuerdo con las condiciones del contrato. El revellin del lienzo Norte conserva una terminación almenada, de ladrillo macizo, realizada probablemente del siglo XVIII o mediados del XVII. En 1973 se realiza una ampliación del grupo escolar Luis vives, y tres años más tarde se construirían los jardines y la pista de juegos al exterior del recinto, frente al Portal de Valencia.

En el año 1987 unas importantes lluvias causaron serios destrozos en la zona norte de la muralla, entre el portal de Valencia y el revellín Norte, dejando al descubierto la tierra apisonada de su interior. Se realizó, de inmediato, una reparación de emergencia para impedir el acceso del agua a su interior, lo que habría supuesto el desmoronamiento total del muro, con unas lechadas de cal que tuvieron un excelente comportamiento, ya que, por diversas circunstancias las obras de restauración, no se iniciarían hasta el año 2008.

\subsection{La operación de recuperación de la tapia valenciana en 2008}

El proyecto y obra de restauración que acomete el arquitecto y profesor D.Francisco Taberner Pastor en el año 2008, se ajusta a la sección de tapia arruinada, que era parte de la restauración realizada por Regiones Devastadas que reconstruyó la tapia sustituyendo los ladrillos del calicostrado por mampuestos, distinguiéndose con facilidad de la parte más antigua, que al igual que en otras zonas de la muralla, conserva su factura original dejando entrever ladrillos.

En dichas obras de restauración se optó por utilizar el método tradicional, tratando de recomponer las cinco tapiadas originales, de $3,70 \times 1,15$, levantando el muro de nuevo. Se desechó la idea inicial de demoler parte del muro para rehacer tapias completas, y se montaron los tapiales iniciándose los trabajos de vertido y compactación del material, uniendo la obra nueva con la antigua mediante varillas de acero inoxidable. La tierra se humedecía en hormigonera recibiendo un pequeño aporte de cal, y se compactaba mediante un pisón manual. El mortero de cal, mezclado con la tierra del lugar, y una pequeña porción de cemento blanco para acelerar su fraguado, adoptó un tono ligeramente sonrosado, que es el que conserva en la actualidad.

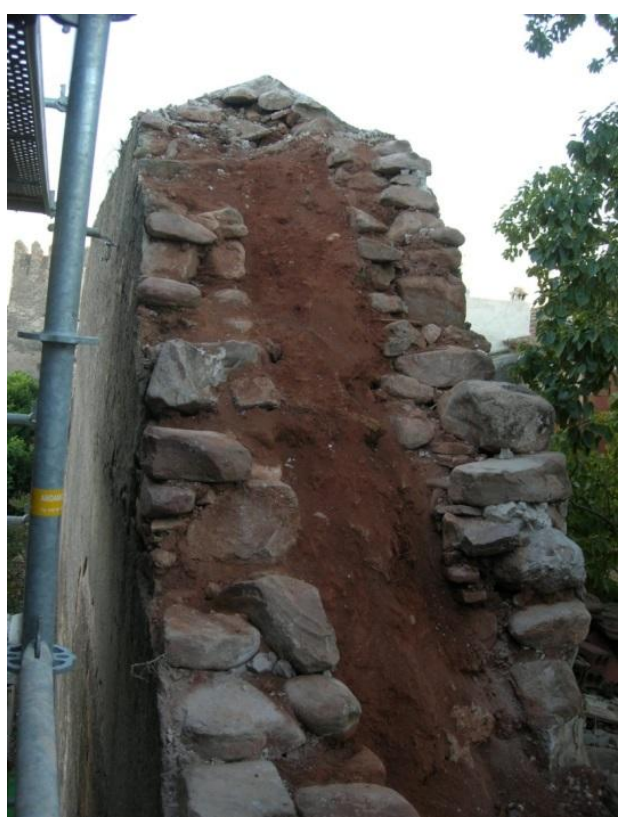

Fig. 4.- Sección de la tapia en la parte reconstruida en 1942 por Regiones Devastadas.

La mayor complejidad de la obra consistió en la colocación de las tapias, y de los necesarios andamios, en la parte interior del recinto, en donde hubo que desmontar o apuntalar diversas construcciones secundarias que a lo largo del tiempo se habían ido realizando junto a la muralla, a veces utilizándola como punto de apoyo de vigas y en ocasiones picando su cara interior, quedando el muro reducido tan sólo a la parte exterior del calicostrado que se mantenía en milagroso equilibrio. 
Llevando a cabo el remate del muro tal como se describía en el primitivo contrato, es decir de cal $y$ canto, $y$ en forma de esquena de gat.
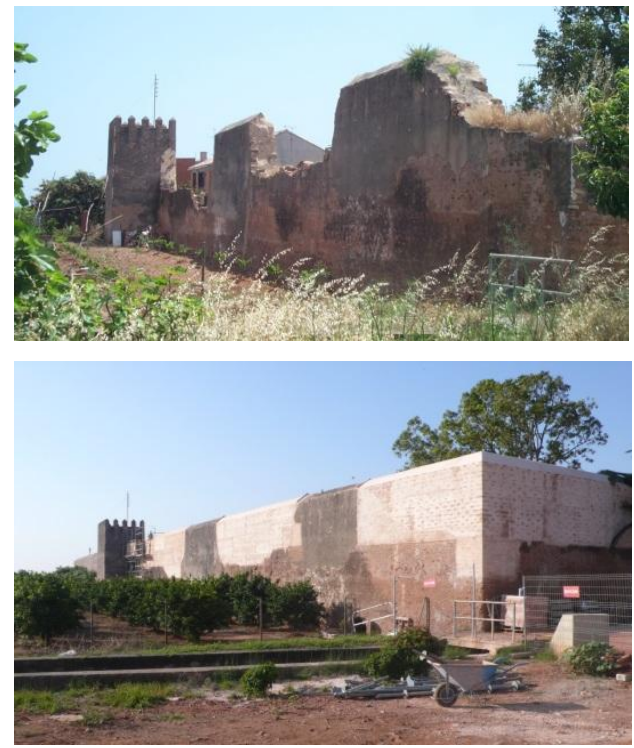

Fig.5.- Estado del muro previo a la restauración y tras las obras efectuadas en 2008.

\section{Las obras de consolidación y puesta en valor de 2015}

Financiadas por el Ministerio de Fomento y por la Entidades del sector público dependientes o vinculadas, conforme a la Orden FOM/1932/2014, de 30 de septiembre, se está desarrollando actualmente la última actuación de consolidación de $40 \mathrm{~m}$ de muralla, con un presupuesto de licitación de 96.100 euros.

\subsection{Estado inicial de la muralla}

El estado del muro previo a la actual intervención de 2015, presentaba importantes oquedades y transformaciones y había seguido sufriendo agresiones, continuas a lo largo de su historia: utilización como elemento portante de forjados empotrados en su paramento interior, humedades en su zona de asiento, apertura de huecos y deterioro generalizado de su coronación, lo que la ha convertido en un elemento fácilmente degradable, que ha requerido y requiere de actuación continuas sobre la misma para frenar su progresivo deterioro.

Como circunstancia adicional que agrava esta circunstancia, el cementerio de Mascarell se encontró adosado al lienzo sur de la muralla, hasta su traslado a finales del s. XX, lo que trajo la perforación de la muralla en la necesidad de espacio para los féretros.

Salvo las áreas de muralla restituidas en 2008, el perímetro amurallado de Mascarell seguía precisando de su restauración integral.

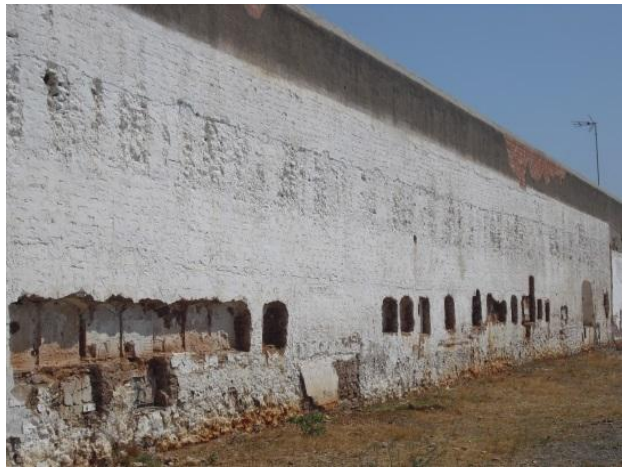

Fig.6.- Vista del lienzo sur de la muralla, donde estuvo adosado el cementerio de Mascarell.

\subsection{Descripción del proyecto: la adaptación arquitectónica al entorno}

El proyecto, redactado por los arquitectos Francisco Taberner e Ignacio Gómez-Ferrer, basado en un estudio riguroso de esta parte de nuestro patrimonio, persigue la consolidación, restauración y puesta en valor de la muralla en su frente Sur Oeste, mediante una serie de actuaciones, como son: la retirada de elementos impropios, tales como postes, farolas, cableado, etc.; el desmontado de antiguas restituciones de trozos caídos de muralla que fueron restituidos a base de fábrica de ladrillo enfoscada; el saneado y limpieza de paramentos; la restitución de oquedades mediante tapial y el retacado del zócalo de mampuestos.

Asimismo se propone la integración cromática de los ámbitos reparados y la eliminación de sobreelevación de construcciones adosadas a la muralla. 
Otros elementos objetos de restauración en el proyecto son los portales, las torres con la eliminación de las almenas actuales, añadidas a mediados del s.XX, originalmente inexistentes y el encargo de un estudio arqueológico tanto de la muralla como de su entorno próximo, como base para la creación de una zona de afección del entorno a la muralla, de modo que se posibilite su visión exenta y se permita su paseo perimetral.

\subsection{El desarrollo de las obras}

Las obras, que se iniciaron en noviembre de 2014, están actualmente en desarrollo, bajo la dirección de los mismos arquitectos que redactan el proyecto.

En la actual fase de obra se está acometiendo la demolición de las partes del muro reconstruidas en ladrillo, que como se ha comprobado in situ, servía únicamente de encofrado perdido para un contundente zuncho de hormigón armado que servía de atado a las partes reconstruidas.

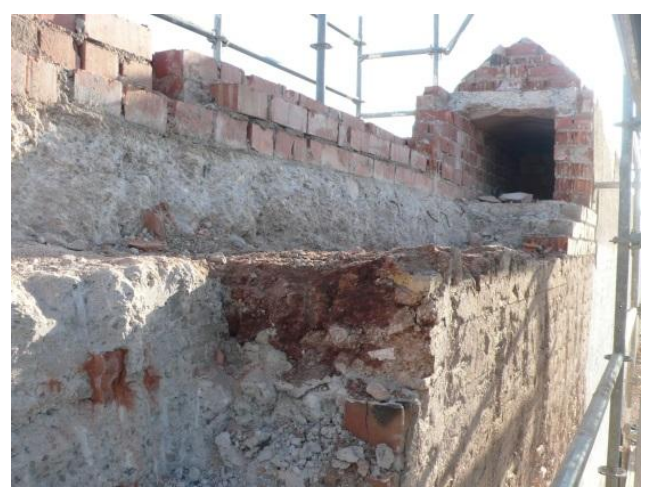

Fig.7.- Vista tomada en una de las fases constructivas de las actuales obras de restauración (2015), donde se aprecia el zuncho de hormigón armado de la desafortunada restauración acometida en los años 70 .

\section{Conclusiones: estado actual, propuestas de mejora para la futura conservación}

El proyecto de 2014, viene sin duda a subsanar parcialmente la urgente necesidad que se ha tenido de un Plan Director (7), dado que contempla en parte sus requerimientos, como la recuperación del estado inicial de la muralla, el cerramiento de sus huecos impropios y la sustitución de las desafortunadas reparaciones de ladrillo macizo de los años 70 del pasado siglo por nueva fábrica de tapia.

No obstante más intervenciones son necesarias: se debería establecer el acceso a los revellines, reponiendo sus escaleras y retirar las construcciones que se apoyan o penetran en el muro. Igualmente se haría necesario recuperar el nivel originario del paramento del portal de Valencia, retirando la actual plantación de palmeras, y estableciendo un sistema de iluminación adecuado.

Considerando los proyectos parciales de obra, soluciones de urgencia necesarias para este elemento de nuestro patrimonio, no se debe descartar, la necesidad del plan director como programa para los futuros trabajos de mantenimiento y mejora, y para lo que hoy en día debería ser norma, un documento base para conocer las partidas presupuestarias que la administración competente debe reservar o financiar para el mantenimiento a lo largo del tiempo de este importante bien de interés cultural.

\section{Notas}

(1)Primera valoración positiva del conjunto amurallado.

(2) El Contrato de obras de Mascarell se caracteriza porque su mayor interés radica fundamentalmente en la datación precisa de la obra y la descripción de su método.

(3) La protección de los conjuntos históricos nace en el intento de superar la visión monumental de la conservación arquitectónica, con una nueva mirada ambiental: no más edificios aislados, sino una continuidad de edificios que se conservan en un contexto.

(4) Afecta, aún a los conjuntos declarados con anterioridad a la LPHE, ya que es de aplicación la disposición adicional primera, en la que se dispone que "los bienes declarados al amparo de la legislación anterior, pasarán a tener la consideración y a denominarse bienes de interés cultural $[\ldots]$ todos ellos quedarán sometidas al 
régimen jurídico que para estos bienes la presente ley establece".

(5) Artículo 20.1 de la LPHE, "la declaración de un conjunto histórico determinará la obligación para el municipio o municipios en que se encuentren de redactar un plan especial de protección del área afectada por la declaración u otro instrumento de planeamiento de los previstos en la legislación urbanística".

(6) El artículo 21.1 de la LPHE que establece que "en los instrumentos de planeamiento relativos a Conjuntos Históricos se realizará la catalogación, según la legislación urbanística, de los elementos unitarios que conforman el conjunto, tanto inmuebles edificados como espacios libre exteriores o interiores, $\mathrm{u}$ otras estructuras significativas, así como de los componentes naturales que lo acompañan, definiendo los tipos de intervención posible. A los elementos especiales se les dispensará una protección integral. Para el resto de elementos se fijará, en cada caso, un nivel adecuado de protección".

(7)Son escasas las poblaciones que conservan su entorno amurallado libre de obstáculos que impidan su visión. Ésa singularidad supone una mayor valoración de interés por el conjunto, que debe de ser aprovechada para extraer una mayor rentabilidad del mismo. Rentabilidad cultural orientando la mirada sobre este importante patrimonio, rentabilidad social y rentabilidad económica que puede deducirse de la transformación de lo que hoy es un barrio marginado de la ciudad.

\section{Referencias}

Algorri García, E., Vázquez Espí, M. (1991) “Palacio de Toral de los Guzmanes”, en XIII Curso sobre la intervención en el Patrimonio arquitectónico del COAC.

Alonso Ibáñez, M. (2005), Los catálogos urbanísticos y otros catálogos protectores del Patrimonio cultural Inmueble. Aranzadi.

Bauluz del Río, G., Bárcenas Barrios, P. (1992) Bases para el diseño y construcción del tapial. MOPT.

Barrero Rodríguez, C. (2006), La ordenación urbanística de los conjuntos históricos. Iustel. Madrid.

Campesino Fernández, A.J. (1989) "La rehabilitación integrada de los centros históricos: el reto urbanístico de finales de los ochenta", Edición digital a partir de Investigaciones Geográficas, $\mathrm{n}^{\circ} 7$, pp.7-17.

Casar Furió, E. (2010), Régimen Jurídico de los Bienes Inmuebles de interés Cultural en la Legislación Valenciana. Tirant monografías, Valencia.

Font, F., Hidalgo P. El tapial. Una tècnica constructiva mil.lenària. Ed, de los autores. Castellón.

Gomez Ferrer, M. (2002), Las murallas de Mascarell. Boletín de la Sociedad Castellonense de Cultura. Tomo LXXVIII. Enero-junio, pp.213-224.

López Jaen, J. (1990) “Los centros históricos españoles”. Urbanismo, nº, pp.14- 24.

Fernández, R. (1990), “Un programa de planeamiento en centros históricos”. en Urbanismo, $n^{\circ} 9$, pp.54-56.

García y Bellido, Torres Balbás, Cervera, Chueca, Bidagor. (1986), Resumen histórico del Urbanismo en España. IEAL. Madrid.

Rivera Blanco, J. (1997), "Restauración arquitectónica desde los orígenes hasta nuestros días. Conceptos, teoría e historia", En: Teoría e historia de la restauración. Master de restauración y rehabilitación del patrimonio .Ed Munilla-Lería, Madrid.

Taberner Pastor, F. (2004), La evolución de los criterios de protección en el patrimonio arquitectónico: del monumento histórico-Artístico al valor cultural. U. Politécnica de Valencia.

Taberner Pastor, F. (2008), Proyecto de consolidación y puesta en valor del lienzo de las murallas de Mascarell. Septiembre.

Taberner Pastor F. (2012), "Valencian tapia in the walled city of Mascarell (Castellón, Spain)". En Restapia 2012. Rammed Earth Conservation. Taylor\&Francis Group, London. 
Taberner, P., Broseta M.T. (2011-12), "La defensa y recuperación del conjunto histórico de Mascarell”, en Arché, Publicación del Instituto Universitario de Restauración del Patrimonio, Universidad Politécnica de Valencia, 2011-2012.

Termes, V., Barrios, R. (1933), "La construcción del tapial en la provincia de Albacete", en Revista arquitectura $n^{\circ} 178$. Madrid. 